\title{
Paclitaxel Against Cancer: A Short Review
}

\section{Priyadarshini $\mathrm{K}^{1 *}$ and Keerthi Aparajitha $\mathrm{U}^{2}$}

${ }^{1}$ Department of Biotechnology, JSS College for Arts Commerce \& Science, Mysore, India

${ }^{2}$ Department of Biotechnology, Loyola Academy Degree \& PG College, Secunderabad, India

\begin{abstract}
Cancer is a life threatening condition. Though it has been immensely studied in the field of medical research, not all attempts have been fruitful. More than half the people diagnosed with cancer receive chemotherapy. One such effective discovery leads to Paclitaxel, a Pacific Yew tree isolate. This review makes attempt at understanding a few advancements in cancer treatment using Paclitaxel since its discovery. We await the discovery of many such compounds which make an impact in cancer treatment. This review tried to discuss the various research using Paclitaxel and its efficacy against various types of cancers and stresses on the need for the research in the field of Cancer Chemotherapy.
\end{abstract}

Keywords: Paclitaxel; Cancer; Chemotherapy

\section{Introduction}

Monroe E. Wall and Mansukh C. Wani in 1967 isolated a mitotic inhibitor from the bark of Taxus brevifolia (northwest Pacific Yew Tree) (Figure 1) and named this compound Taxol. It was later discovered that the Taxol was produced by a fungal endophyte when grown on semisynthetic media. The fungal endophyte was isolated from the phloem tissue of the Pacific Yew Tree [1]. It was first commercially developed by Bristol-Myers Squibb Company with the generic name Paclitaxel and sold under the trademark Taxol. Several formulations were later developed in this field by conjugating Paclitaxel with albumin, Polycitrate etc., from each Taxus tree, 150 strains of endophytic fungi were isolated. The endophytic fungal population is varied. 105 out of 150 strains belonged to 25 different genera whereas one remains undetermined and $44 \mathrm{did}$ not produce any reproductive structure in solid cultures [2].

Paclitaxel is a crystalline powder which is white to off-white in appearance. Its empirical formula is $\mathrm{C}_{47} \mathrm{H}_{51} \mathrm{NO}_{14}$ (Figure 2) and is known to have a molecular weight of 853.9 units. It is highly lipophilic thus highly insoluble in water. Its melting point is around $216-217^{\circ} \mathrm{C}$.

\section{Mechanism of Action}

Paclitaxel drug targets tubulin. Researchers have observed that Paclitaxel treated cells have difficulty with the spindle assembly, cell division and also chromosome segregation which is in opposing nature to Colchicine, a drug that targets tubulin. The major difference between

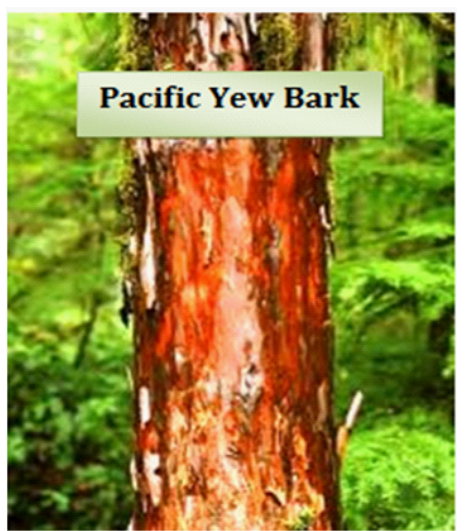

Figure 1: A glimpse of Taxus brevifolia bark.

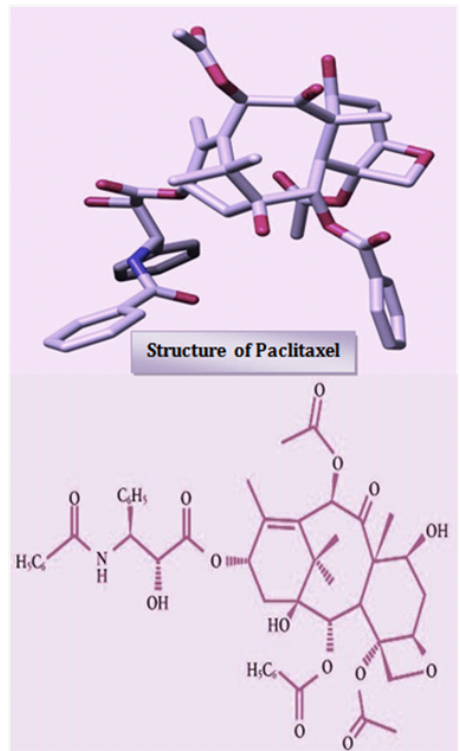

Figure 2: Structure of the drug Paclitaxel.

Colchicine and Paclitaxel is that Colchicine inhibits the microtubule assembly whereas Paclitaxel stabilizes and protects microtubule against disassembly. At a higher dose, Paclitaxel is known to suppress microtubule minus ends detachment from centrosomes [3-5]. The beta-tubulin subunit is known to have the binding site for Paclitaxel [6].

\section{Role of Paclitexal in Inhibiting Various Types of Cancer}

Extensive studies have been done in the field of cancer treatment, especially in the use of various chemotherapeutic agents.

*Corresponding author: Priyadarshini K, Department of Biotechnology, JSS College for Arts Commerce \& Science, Mysore, India, E-mail: prits_bhargav88@yahoo.com

Received November 16, 2012; Accepted November 28, 2012; Published November 30, 2012

Citation: Priyadarshini K, Keerthi Aparajitha U (2012) Paclitaxel Against Cancer: A Short Review. Med chem 2:139-141. doi:10.4172/2161-0444.1000130

Copyright: @ 2012 Priyadarshini K, et al. This is an open-access article distributed under the terms of the Creative Commons Attribution License, which permits unrestricted use, distribution, and reproduction in any medium, provided the original author and source are credited. 
Nanoparticle assisted chemotherapeutic drug delivery has been used as it enhances therapeutic effectiveness. Studies on metastatic breast cancer demonstrates the inhibition of metastasis by co-delivering chemotherapeutic agent Paclitaxel and twist shRNA via complex nanoparticles thus affectively achieving cellular uptake, RNA interference and inhibited metastasis [7]. Administration of Paclitaxelloaded expansile nanoparticles (pax-eNP) at the time of cytoreductive surgery effectively decreased local tumor recurrence in Ovarian Carcinoma [8]. Chemotherapeutic nanoparticles provide an advantage over free drugs as they achieve slower clearance and accuracy in target delivery [9]. However, chemoresistance has been observed in various cancer types, including breast, lung, prostate, ovarian, and neck carcinomas. Nanoparticles conjugated with Paclitaxels can also be delivered as nanomicelles and these formulations can be simply uptaken by intracellular endocytosis which showed higher rate of efficiency in drug delivery to the target tumor when compared to other formulations $[10,11]$. Multiwalled carbon nanotubes have also been used as potential drug delivery systems where Paclitaxel has been conjugated with poly citric acid.

Use of an inhibitor against an activating mutation of signaling molecule in combination with a standard chemotherapeutic agent such as Paclitaxel showed synergistic activity in mutant human endometrial cancer cell lines [12]. A study performed to evaluate the cytotoxic effects of Paclitaxel in combination with Etoposide in Osteosarcoma cells to thermochemotherapy showed that the apoptosis inducing capacity of the drug combination was stronger than the effect of drugs when used individually [13]. A study demonstrates an enhanced Paclitaxel activity in conjugation with gelomulide $\mathrm{K}$, a caspase-independent cell death inducing agent providing an insight into the development of new caspase-independent cell death-inducing agents [14]. Involvement of many target signal transducers as targets to inhibit metastasis by a chemotherapeutic target is being studied for their ability to either mutate, activate or inhibit to suppress the tumor [15-20].

Despite various efforts, multiple myeloma remains incurable. Thus in most cases, combination of chemotherapeutic drugs have been used in order to increase the efficiency. Mostly Paclitaxel synergized with farnesyltransferase inhibitor R115777 (Zarnestra) was found effective enough to induce G2/M cell cycle arrest [21]. Due to hypersensitivity reactions and altered pharmacokinetics of Paclitaxel in combination with Cremophor EL, ABI-007, a Cremophor-free, albumin-stabilized, nanoparticle paclitaxel formulation was used and found to have less toxicity in comparison to Cremophor-containing Paclitaxel in mice [22]. In a study conducted, use of an oral paclitaxel formulation based on thiolated polycarbophil showed significant improved paclitaxel plasma levels and reduced tumor growth [23].

Paclitaxel in various studies is showed as effective anticancer agent against lung, breast, ovarian, leukopenia and liver cancer [24-29]. It is also known to produce macrophage IL-12 in tumor bearing hosts which down regulates the tumor growth significantly by selective dysregulation of IL-12 p40 expression [30]. It is also known to reduce glycolysis by specific mechanisms [31]. Paclitaxel has a role in treating various kinds of cancer by targeting tubulin or inducing cell cycle arrest or enhancing the signaling factors or mutating them [32-40]. Unfortunately the high demand for Taxol from the bark of Pacific yew is a challenging aspect for this new therapeutic weapon [41]. Therefore focus should be on developing this product by chemical/ synthetic methods in order to meet the growing need of this anticancer drug.

\section{Conclusion}

Paclitaxel is a very potent anticancer agent obtained from the Pacific
Yew tree bark. It seems to raise its efficacy by having multi targets as described earlier, thus being effective against most cancers. This drug has been studied extensively since 1967, from the time of its discovery till date. The main drawback seems to be the mass production of this drug, which can be resolved by focusing more on either chemical/ microbial synthesis of Paclitaxel for the clinical use.

\section{References}

1. Stierle A, Strobel G, Stierle D (1993) Taxol and taxane production by Taxomyces andreanae, an endophytic fungus of Pacific yew. Science 260: 214-216.

2. Carsuso M, Colombo AL, Fedeli L, Pavesi A, Quaroni S, et al. (2000) Isolation of endophytic fungi and actinomycetes taxane producers. Ann Microbiol 50: 3-13.

3. Bharadwaj R, Yu H (2004) The spindle checkpoint, aneuploidy, and cancer Oncogene 23: 2016-2027.

4. Brito DA, Yang Z, Rieder CL (2008) Microtubules do not promote mitotic slippage when the spindle assembly checkpoint cannot be satisfied. J Cell Biol 182: 623-629.

5. Ganguly A, Yang H, Cabral F (2010) Paclitaxel-dependent cell lines reveal a novel drug activity. Mol Cancer Ther 9: 2914-2923.

6. Löwe J, Li H, Downing KH, Nogales E (2001) Refined structure of alpha betatubulin at 3.5 A resolution. J Mol Biol 313: 1045-1057

7. Shen J, Sun $H, X u P$, Yin Q, Zhang Z, et al. (2012) Simultaneous inhibition of metastasis and growth of breast cancer by co-delivery of twist shRNA and Paclitaxel using pluronic P85-PEI/TPGS complex nanoparticles. Biomaterials S0142-9612(12)01208-2

8. Gilmore D, Schulz M, Liu R, Zubris KA, Padera RF, et al. (2012) Cytoreductive Surgery and Intraoperative Administration of Paclitaxel-loaded Expansile Nanoparticles Delay Tumor Recurrence in Ovarian Carcinoma. Ann Surg Oncol.

9. Park S, Kang S, Chen X, Kim EJ, Kim J, et al. (2012) Tumor suppression via Paclitaxel-loaded drug carriers that target inflammation marker upregulated in tumor vasculature and macrophages. Biomaterials 34: 598-605.

10. Li Y, Bi Y, Xi Y, Li L (2012) Enhancement on oral absorption of Paclitaxel by multifunctional pluronic micelles. J Drug Target.

11. Zhang J, Zhao J, Zhang W, Liu G, Yin D, et al. (2012) Establishment of Paclitaxel-resistant cell line and the underlying mechanism on drug resistance. Int J Gynecol Cancer 22: 1450-1456.

12. Byron SA, Loch DC, Pollock PM (2012) Fibroblast growth factor receptor inhibition synergizes with Paclitaxel and Doxorubicin in endometrial cancer cells. Int J Gynecol Cancer 22: 1517-1526.

13. Huang T, Gong WH, Li XC, Zou CP, Jiang GJ, et al. (2012) Synergistic increase in the sensitivity of osteosarcoma cells to thermochemotherapy with combination of Paclitaxel and etoposide. Mol Med Report 6: 1013-1017.

14. Yang JC, Lu MC, Lee CL, Chen GY, Lin YY, et al. (2011) Selective targeting of breast cancer cells through ROS-mediated mechanisms potentiates the lethality of Paclitaxel by a novel diterpene, gelomulide K. Free Radic Biol Med 51: 641-657.

15. Barz M, Armiñán A, Canal $F$, Wolf $F$, Koynov $K$, et al. (2012) $P(H P M A)$-block$\mathrm{P}(\mathrm{LA})$ copolymers in Paclitaxel formulations: Polylactide stereochemistry controls micellization, cellular uptake kinetics, intracellular localization and drug efficiency. J Control Release 163: 63-74.

16. Sobhani Z, Dinarvand R, Atyabi F, Ghahremani M, Adeli M (2011) Increased Paclitaxel cytotoxicity against cancer cell lines using a novel functionalized carbon nanotube. Int J Nanomedicine 6: 705-719.

17. Pölcher M, Eckhardt M, Coch C, Wolfgarten M, Kübler K, et al. (2010) Sorafenib in combination with carboplatin and Paclitaxel as neoadjuvant chemotherapy in patients with advanced ovarian cancer. Cancer Chemother Pharmacol 66: 203-207.

18. Kang HJ, Lee SH, Price JE, Kim LS (2009) Curcumin suppresses the Paclitaxel-induced nuclear factor-kappaB in breast cancer cells and potentiates the growth inhibitory effect of Paclitaxel in a breast cancer nude mice model Breast J 15: 223-229.

19. Lim SJ, Choi MK, Kim MJ, Kim JK (2009) Alpha-tocopheryl succinate potentiates the Paclitaxel-induced apoptosis through enforced caspase 8 activation in human $\mathrm{H} 460$ lung cancer cells. Exp Mol Med 41: 737-745. 
Citation: Priyadarshini K, Keerthi Aparajitha U (2012) Paclitaxel Against Cancer: A Short Review. Med chem 2:139-141. doi:10.4172/21610444.1000130

20. Zhang SQ, Chen GH (2009) Determination of a novel Paclitaxel derivative (NPD-103) in human plasma by ultra-performance liquid chromatographytandem mass spectrometry. Biomed Chromatogr 23: 510-515.

21. Zhu K, Gerbino E, Beaupre DM, Mackley PA, Muro-Cacho C, et al. (2005) Farnesyltransferase inhibitor R115777 (Zarnestra, Tipifarnib) synergizes with Paclitaxel to induce apoptosis and mitotic arrest and to inhibit tumor growth of multiple myeloma cells. Blood 105: 4759-4766.

22. Scripture CD, Figg WD, Sparreboom A (2005) Paclitaxel chemotherapy: from empiricism to a mechanism-based formulation strategy. Ther Clin Risk Manag 1: 107-114.

23. Föger $F$, Malaivijitnond $S$, Wannaprasert $T$, Huck $C$, Bernkop-Schnürch $A$, et al. (2008) Effect of a thiolated polymer on oral Paclitaxel absorption and tumor growth in rats. J Drug Target 16: 149-155.

24. Yen WC, Corpuz MR, Prudente RY, Cooke TA, Bissonnette RP, et al. (2004) A selective retinoid $X$ receptor agonist bexarotene (Targretin) prevents and overcomes acquired Paclitaxel (Taxol) resistance in human non-small cell lung cancer. Clin Cancer Res 10: 8656-8664.

25. Hood KA, West LM, Rouwé B, Northcote PT, Berridge MV, et al. (2002) Peloruside A, a novel antimitotic agent with Paclitaxel-like microtubulestabilizing activity. Cancer Res 62: 3346-3360.

26. Beulz-Riché D, Robert J, Riché C, Ratanasavanh D (2002) Effects of Paclitaxel, cyclophosphamide, ifosfamide, tamoxifen and cyclosporine on the metabolism of methoxymorpholinodoxorubicin in human liver microsomes. Cancer Chemother Pharmacol 49: 274-280.

27. Lee FY, Borzilleri R, Fairchild CR, Kim SH, Long BH, et al. (2001) BMS247550: a novel epothilone analog with a mode of action similar to Paclitaxe but possessing superior antitumor efficacy. Clin Cancer Res 7: 1429-1437.

28. Yasuda M, Kimura E, Ochiai K, Tada S, Udagawa Y, et al. (2001) [Dose finding study of Paclitaxel and carboplatin for ovarian cancer (JKTB)]. Gan To Kagaku Ryoho 28: 493-498.

29. Minami H, Sasaki Y, Watanabe T, Ogawa M (2001) Pharmacodynamic modeling of the entire time course of leukopenia after a 3-hour infusion of Paclitaxel. Jpn J Cancer Res 92: 231-238.
30. Mullins DW, Burger CJ, Elgert KD (1999) Paclitaxel enhances macrophage IL-12 production in tumor-bearing hosts through nitric oxide. J Immunol 162: 6811-6818.

31. Glass-Marmor L, Beitner R (1999) Taxol (Paclitaxel) induces a detachment of phosphofructokinase from cytoskeleton of melanoma cells and decreases the levels of glucose 1,6-bisphosphate, fructose 1,6-bisphosphate and ATP. Eur J Pharmacol 370: 195-199.

32. Cragg GM (1998) Paclitaxel (Taxol): a success story with valuable lessons for natural product drug discovery and development. Med Res Rev 18: 315-331.

33. Long BH, Carboni JM, Wasserman AJ, Cornell LA, Casazza AM, et al. (1998) Eleutherobin, a novel cytotoxic agent that induces tubulin polymerization, is similar to Paclitaxel (Taxol). Cancer Res 58: 1111-1115.

34. Plasswilm L, Cordes N, Fietkau R, Sauer R (1998) Cytotoxicity of fractionated Paclitaxel (Taxol) administration in vitro. Strahlenther Onkol 174: 37-42.

35. Wenk MR, Fahr A, Reszka R, Seelig J (1996) Paclitaxel partitioning into lipid bilayers. J Pharm Sci 85: 228-231.

36. Spencer CM, Faulds D (1994) Paclitaxel. A review of its pharmacodynamic and pharmacokinetic properties and therapeutic potential in the treatment of cancer. Drugs 48: 794-847.

37. Kingston DG (1994) Taxol: the chemistry and structure-activity relationships of a novel anticancer agent. Kingston DG. Trends Biotechnol 12: 222-227.

38. Sulkes A, Beller U, Peretz T, Shacter J, Hornreich G, et al. (1994) Taxol: initial Israeli experience with a novel anticancer agent. Isr J Med Sci 30: 70-78.

39. Willey TA, Bekos EJ, Gaver RC, Duncan GF, Tay LK, (1993) High-performance liquid chromatographic procedure for the quantitative determination of Paclitaxel (Taxol) in human plasma. J Chromatogr 621: 231-238.

40. Rowinsky EK, Cazenave LA, Donehower RC (1990) Taxol: a nove investigational antimicrotubule agent. J Natl Cancer Inst 82: 1247-1259.

41. Markman M (1991) Taxol: an important new drug in the management of epithelial ovarian cancer. Yale J Biol Med 64: 583-590. 